\title{
Roles of Oxygen for Methanol Adsorption on Polycrystalline Copper Surface Revealed by Sum Frequency Generation Imaging Microscopy
}

\author{
Ming Fang, Greggy Santos ${ }^{1}$, Xiaole Chen ${ }^{2}$, and Steven Baldelli* \\ Department of Chemistry, University of Houston, Houston, Texas, 77204-5003, United States
}

\begin{abstract}
The adsorption of atmospheric pressure methanol on the polycrystalline copper surface has been studied by a combination of sum frequency generation imaging microscopy (SFGIM) and temperature programmed desorption (TPD). Methoxy species can be generated by exposing the polycrystalline copper surface to methanol vapor at room temperature. SFGIM results demonstrate that oxygen promotes the surface adsorption of methanol and the increase in the amount of methoxy produced on copper surface. SFGIM orientation analysis suggests the methoxy monolayer is oriented closer to the surface normal with introduction of oxygen. Employing the image statistical analysis approach, the heterogeneities and conformation distribution of methoxy monolayers on copper surface with and without oxygen adsorption are compared. These results illustrate SFGIM indeed could provide more insight for understanding the heterogeneous metal/metal oxide surface in the molecular level.
\end{abstract}

Keywords: Methanol, Copper, Microscopy, Adsorption, Vibrational spectroscopy, Catalysis

\section{Introduction}

The adsorption of methanol on metal surfaces has been widely studied as a model system in both fundamental surface science and industry due to a number of relevant heterogeneous catalytic reactions such as hydrogenation of $\mathrm{CO}$ to methanol and syntheses of formaldehyde.[1-5] The methoxy fragment is always produced following methanol adsorption as a stable and abundant species at room temperature and it has been proved to be an important intermediate during

${ }^{*}$ Corresponding author.

Email address: sbaldelli@uh.edu

${ }^{1}$ Department of Electrical and Computer Engineering, University of Houston, Houston,Texas,77204-5003, United States

${ }^{2}$ Department of Chemistry and Biochemistry, University of Texas at Austin, Austin, Texas, 78712-1224, United States 
industrial methanol and formaldehyde production with well-documented use of metal and metal oxide catalysts.[2,6] The generation of methoxy group requires copper atoms to induce metal activated $\mathrm{O}-\mathrm{H}$ bond scission on the adsorbed methanol atom. In many cases, such process can be promoted with the assistance of the adsorbed oxygen. [2, 6-9] However, in some conditions the formate group is identified on copper surface as a less abundant but more stable intermediate following methanol adsorption.[4, 10]

A variety of surface science techniques have been performed to detect methanol adsorption on the copper surface, such as Electron Energy Loss Spectroscopy (EELS), Low Energy Electron Diffraction (LEED), Auger Electron Spectroscopy(AES), X-ray Photoelectron Spectroscopy (XPS) and Temperature Programmed Desorption (TPD).[6-8, 11-13] While these traditional surface science techniques could only be operated in ultra-high vacuum (UHV) conditions, with a large enough free mean path for the ion or electron to reach the sample or be collected by detectors, many interesting surface phenomena including the adsorption of methanol were uncovered.[14, 15] However, realistic heterogeneous catalytic reactions are mostly carried out in a high pressure environment, which are essential in understanding the mechanism of methanol adsorption under atmospheric pressure. Vibrational spectroscopy is generally a very powerful tool to deduce the chemical identity and structure of adsorbates on the surface. Nevertheless spectroscopic studies are typically based on an assumption that metal surface is homogenous within the involved field-of-view on the sample. By analyzing an average response over the probe area without any spatial resolution, local heterogeneities (i.e., surface defects, molecular coverage, chemical composition, etc.) would be overlooked. Even though scanning probe microscope (SPM) studies (i.e., atomic force microscope and scanning tunnel microscope) have investigated the copper surface with atomic resolution, these techniques could only provide a limited range of chemical information.[16, 17] Thus modeling of methanol adsorption on the heterogeneous metal surface, emphasizes the importance of in-situ molecular level spectroscopic studies of adsorbed species with spatial resolution under practical catalytic conditions.

Sum frequency generation (SFG), as a vibrational spectroscopic technique, provides chemical information through a more specific identification of chemical functionalities and conformational order of molecular layer within a broad 
temperature and pressure range. Comparing with other linear vibrational spectroscopy techniques such as IRAS, and EELS, SFG is intrinsically surface sensitive based on the fact that this second-order nonlinear optical process is forbidden in isotropic medium. Various catalytic reactions such as $\mathrm{CO}$ oxidation[18] and hydrocarbon conversion[19] on transition metals has been successfully investigated by SFG, which demonstrates its applicability for studying gas interaction with metal surface. Lin, et al. employed the SFG to in-situ probe the polycrystalline copper surface during methanol synthesis and identified the formation of formate intermediate on copper surface.[10] Shultz et al. applied SFG to identify the methanol and methoxy species on anatase $\mathrm{TiO} 2$ nanoparticle film.[20] A very recent study, using SFG vibrational spectroscopy to study the dissociation and photo-oxidation reaction of $\mathrm{CH}_{3} \mathrm{OH}$ on the $\mathrm{TiO}_{2}$ thin film, demonstrates that $\mathrm{O}_{2}$ promotes $\mathrm{CH}_{3} \mathrm{OH}$ dissociation and produces more methoxy adsorbed on the $\mathrm{TiO} 2$ thin film.[21] Considering the presence of local features and heterogeneities of metal surfaces, SFGIM, shows unique advantages for investigating chemical processes on metal surface with spatial and chemical resolution. $[22,23]$ In this paper, SFGIM has been employed to study the methanol adsorption on polycrystalline copper at atmospheric condition. The aim of this paper is to present the two-dimensional distribution of conformational information of the methoxy monolayer heterogeneity and clarify the role of oxygen in affecting the heterogeneity of the methoxy monolayer and copper surface. From the TPD and SFGIM results, the major surface product, methoxy, is chemically identified and the conformation order of methoxy monolayer is characterized. The oxygen exposure promotes the formation of the methoxy monolayer and, hence, increases the surface density of monolayer with homogeneous arrangement on the copper surface.

\section{Experimental Section}

\subsection{Sum frequency generation process}

In previous works, SFG theory has been described in detail.[24-27] SFG is a second-order nonlinear optical technique involving a frequency tunable midinfrared beam and a fixed pump beam overlapped, spatially and temporally, on the sample surface. To minimize the background noise, the $1064 \mathrm{~nm}$ beam was selected to as the pump beam, instead of $532 \mathrm{~nm}$ which was more common choice 
in previous SFG studies.[28-30] An output beam with a frequency equal to the sum of the two input beams is generated from the surface wherein both total energy and momentum are conserved. In dipole approximation, only certain noncentrosymmetric media (i.e. interfacial monolayers) allow the SFG process to occur. Thus, SFG is a highly surface sensitive technique.[31] In Equation 1, the SFG intensity is proportional to the square of the second-order polarization on the surface. The second-order susceptibility $\chi_{\text {eff }}^{(2)}$ correlates the relationship between the second-order polarization with the intensity of the input beams.

$$
I_{S F} \propto\left|P_{S F}^{(2)}\right|^{2} \propto\left|\chi_{e f f}^{(2)}\right|^{2} I_{1064 \text { nnt } I K}
$$

Equation 2 demonstrates the tensor $\chi_{\text {eff }}^{(2)}$ consists of two terms, which is the nonresonant term $\chi_{N R}^{(2)}$ from the substrate contribution and the resonant term $\chi_{\mathrm{R}}^{(2)}$ from the contribution of interfacial monolayer. The $\chi_{\text {eff }}^{(2)}$ is related to molecular hyperpolarizability $\beta^{(2)}$ through ensemble average over all possible molecular orientations including tilt angle $(\Theta)$, azimuth angle $(\varphi)$, and rotation angle $(\psi)$ as sketched in Figure 1. Equation 3 is the basis equation for the nonlinear curve fitting of the experimental SFG spectra. $N, A_{q}, \omega_{I R}, \omega_{q}$, and $\Gamma_{q}$ denote the surface molecular density, resonant amplitude, IR beam frequency, resonant frequency and the damping factor of the $\mathrm{q}^{\text {th }}$ mode, respectively. When the frequency of the infrared beam $\omega_{I R}$ approaches the resonant frequency of $\mathrm{q}^{\text {th }}$ vibrational mode, the $\chi_{\mathrm{R}}^{(2)}$ drastically changes in magnitude, as well as the SFG intensity, which is presented as a peak or dip in SFG spectra.

$$
\begin{aligned}
& \chi_{e f f}^{(2)}=\chi_{\mathrm{R}}^{(2)}+\chi_{\mathrm{NR}}^{(2)}=\sum_{q} \frac{N\left\langle\beta^{(2)}\right\rangle}{\omega_{q}-\omega_{I R}-i \Gamma_{q}}+\chi_{\mathrm{NR}}^{(2)} \\
& \chi_{e f f}^{(2)}=\sum_{q} \frac{A_{q}}{\omega_{q}-\omega_{I R}-i \Gamma_{q}}+A_{N} R^{i \phi}
\end{aligned}
$$

Metal or semiconductor surfaces usually contribute to a strong non-resonant background $\chi_{N R}^{(2)}$ due to the nearly free electrons in the surface region. As shown in Equation 4, SFG spectra are complicated by the convolution of $\chi_{\mathrm{R}}^{(2)}$ and $\chi_{N R}^{(2)}$, which are both complex number quantities and wavelength dependent $\left(\chi_{N R}^{(2)}\right.$ is 
relatively constant within a narrow frequency range). [24, 32] The $\varepsilon$ and $\delta$ denote phase of $\chi_{\mathrm{R}}^{(2)}$ and $\chi_{N R}^{(2)}$, respectively. The phase difference between $\chi_{\mathrm{R}}^{(2)}$ and $\chi_{N R}^{(2)}$ is named as relative non-resonant phase $\phi$ in Equation 3. Normally each vibration mode has the same relative phase $\phi$. The SFG spectral line-shape transformation at different relative non-resonant phase $(\phi)$ are simulated in Figure S1 of Supporting Informaiton. The non-resonant phase and intensity vary widely on different metals, even with their corresponding metal oxides.[24, 33] The sensitivity of SFG to substrate characteristic is highly advantageous for studying distinct molecular information as an effect of the metal surface properties.[33]

$$
I_{S F} \propto\left|\chi_{e f f}^{(2)}\right|^{2}=\| \chi_{N P}^{(2)}\left|e^{i \varepsilon}+\right| \chi_{R}^{(2)}\left|e^{i \delta\left(\omega_{I R}\right)}\right|^{2}=\left|\chi_{N k}^{(2)}\right|^{2}+\left|\chi_{R}^{(2)}\right|^{2}+2\left|\chi_{N k}^{(2)}\right|\left|\chi_{R}^{(2)}\right| \cos [\varepsilon-\delta]
$$

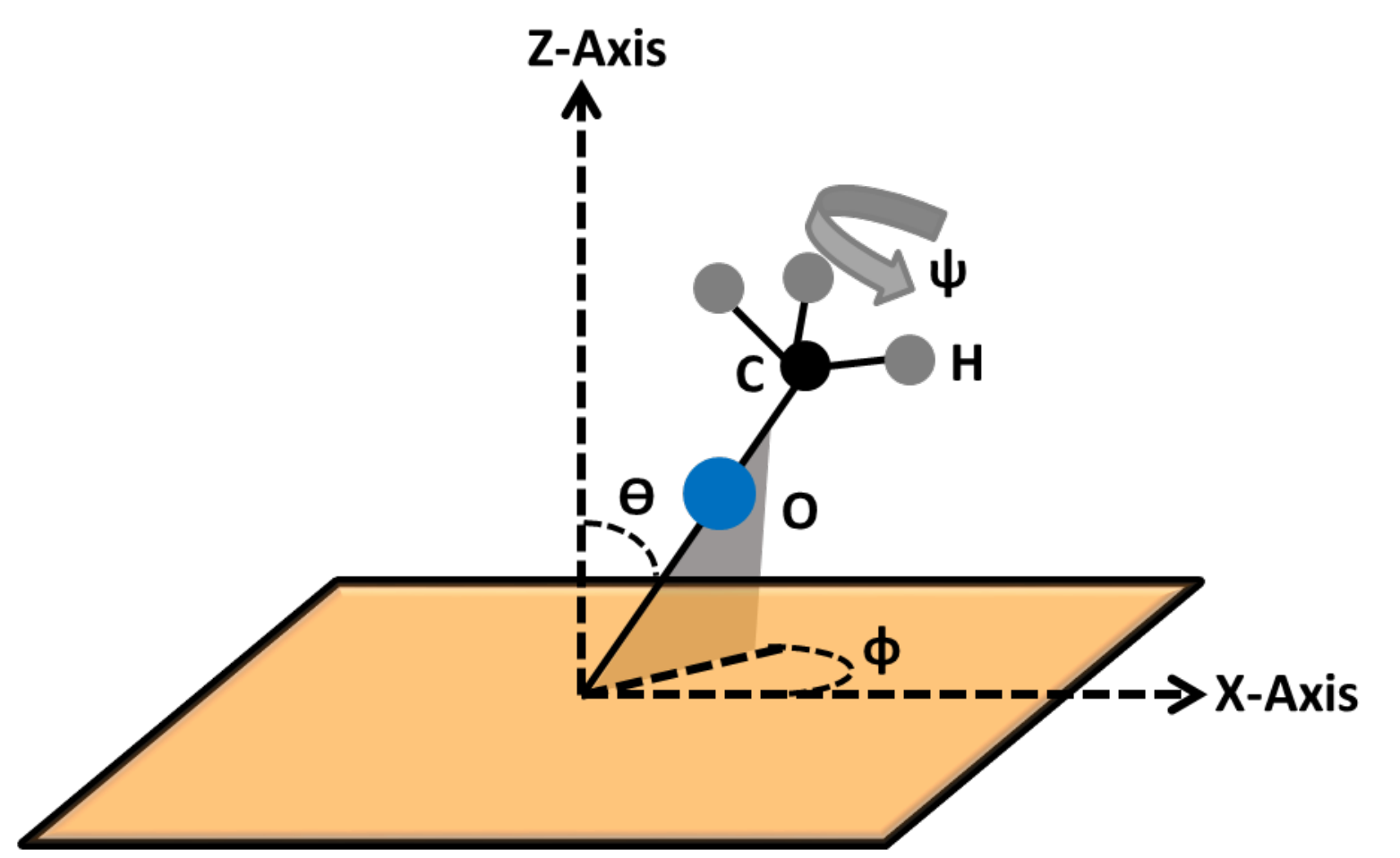

Figure 1. Definition of the tilt angle $(\Theta)$, azimuth angle $(\varphi)$, and rotation angle $(\psi)$ of the methoxy adsorbed on the copper surface.

\subsection{Sample preparation in UHV chamber}

Polycrystalline copper (Goodfellow, 99.99\%) is used as the substrate material. These samples are rectangular with an area of $1 \mathrm{~cm}^{2}$ and a thickness of $3 \mathrm{~mm}$. The samples are polished down to $0.1 \mu \mathrm{m}$ using diamond compound. The copper 
substrates are then mounted on a sample stage supported an $\mathrm{x}-\mathrm{y}-\mathrm{z}$ rotational manipulator housed in a stainless steel UHV chamber. The schematic diagram of the UHV system is shown in Figure S2. This UHV chamber is equipped with a turbo-molecular pump with a base pressure $1 \times 10^{-9}$ Torr. A resistive tungsten filament situated at about $2 \mathrm{~mm}$ at rear of copper surface enables the control of surface temperature from $300 \mathrm{~K}$ to $800 \mathrm{~K}$. Sample temperature measurement is carried out by a K-type thermocouple spot welded on the edge of the copper surface. The surface of the copper substrates are cleaned with several cycles of heating to $800 \mathrm{~K}$ and argon ion sputtering with beam energy of $3000 \mathrm{eV}$. Cleanliness of the metal surface is evaluated by a combination of TPD analysis of the methanol $\left(\mathrm{CD}_{3} \mathrm{OD}\right)$ adsorption and the experimental SFG spectra obtained in $\mathrm{CH}$ stretching region $\left(2750-3000 \mathrm{~cm}^{-1}\right)$. The efficiency of the cleaning procedure is assessed by the extinction of the methylene $\left(-\mathrm{CH}_{2}-\right)$ vibrational peaks at $2850 \mathrm{~cm}^{-1}$ in the SFG spectra (an example shown in Figure S3) that arise from hydrocarbon contaminations. The UHV chamber is coupled to a quadruple mass spectrometer (QMS) (Extorr XT 200) to check the total chamber pressure and partial pressure of molecular fragments. The TPD experiments are carried out by heating the sample at a constant ramp rate $(1 \mathrm{~K} / \mathrm{s})$. Dosing is carried out by backfilling the chamber via a leak valve.

\subsection{SFGIM cell}

The SFGIM cell is connected to the vacuum chamber through a mechanical gate valve. The cell is equipped with $\mathrm{CaF}_{2}$ and quartz windows for the corresponding beam input and output ports, respectively. The IR beam and $1064 \mathrm{~nm}$ pump beam go through the $\mathrm{CaF}_{2}$ window on one side, while the SFG beam emits through the quartz window from opposite side. The sample stage is transferred from the main vacuum chamber into the SFGIM cell using the manipulator. After detaching the sample stage from the manipulator, the gate valve is closed to keep the SFG cell isolated from the main chamber. The methanol $\left(\mathrm{CD}_{3} \mathrm{OD}\right)$ vapor (1 Torr) is introduced into the SFG cell by opening of the needle valve between a glass vessel with SFGIM cell. While being maintained in the glass vessel connected to the SFGIM cell, $\mathrm{CH}_{3} \mathrm{OD}$ (Cambridge Isotopes, 99.8\%D) or $\mathrm{CD}_{3} \mathrm{OD}$ (Cambridge Isotopes, $99 \% \mathrm{D}$ ) are purified through three cycles of: 1) distilling, 2) freezing, 3) thawing and 4) pumping. 


\subsection{SFGIM set up}

SFGIM setup was described in detail elsewhere.[22, 34] The $1064 \mathrm{~nm}$ beam, serves as the pump beam for the SFGIM, is generated by a picosecond pulsed Nd:YAG laser (EKSPLA PL2250) with a $20 \mathrm{~Hz}$ repetition rate. This picosecond laser also pumps the optical parametric generator/amplifier (OPG/OPA) to generate the IR beam, which is tunable within the $2000-4000 \mathrm{~cm}^{-1}$ frequency range. The $1064 \mathrm{~nm}$ beam and IR beam overlap temporally and spatially at incidence angles of $60^{\circ}$ and $70^{\circ}$, respectively. Since the $\chi_{z z z}$ component dominates the SFG process on metal surfaces,[35] the polarization combination named as PPP (the polarization of two incident beams is set to be parallel with the incidence plane, as well as the polarization of SFG beam) is chosen in this work. A reflection configuration is set up with an emission angle of SFG signal at about $62.1^{\circ}$ with respect to the surface normal to collect the intermediated SFG beam profile. A Roper Scientific CCD camera with $1024 \times 1024$ pixel array is used for collecting the magnified SFG beam profile from the sample surface. Each SFG image is composed of $1024 \times 1024$ pixels and each pixel corresponds to about $1 \mu \mathrm{m}$ distance on surface. The approximated spatial resolution for the SFGIM images is $2 \mu \mathrm{m}$.

\section{Results and Discussion}

After dosing with 60 Langmuir of methanol $\left(\mathrm{CH}_{3} \mathrm{OD}\right)$ at $300 \mathrm{~K}$, the TPD results of the methanol $\left(\mathrm{CH}_{3} \mathrm{OD}\right)$ desorption from the polycrystalline copper surface is evaluated at temperatures from 320 to $440 \mathrm{~K}$. Figure 2 shows a TPD profile of the methanol $\left(\mathrm{CH}_{3} \mathrm{OD}\right)$ desorption subjected to a heating rate of $1 \mathrm{~K} / \mathrm{s}$. The chemical species observed in this study are identified by comparing the acquired fragment with those tabulated in the literature.[4, 6, 13, 36] The broad $\mathrm{CH}_{3} \mathrm{OH}$ peak (mass 31 and mass 32) occurs at $340 \mathrm{~K}$. The missing peak of mass 33 indicates the methanol $\left(\mathrm{CH}_{3} \mathrm{OD}\right)$ is desorbed as $\mathrm{CH}_{3} \mathrm{OH}$ instead of $\mathrm{CH}_{3} \mathrm{OD}$. The formaldehyde peak (mass 29 and mass 30) at $350 \mathrm{~K}$ is much higher than the $\mathrm{CH}_{3} \mathrm{OH}$ peak. That suggests that most methanol $\left(\mathrm{CH}_{3} \mathrm{OD}\right)$ species dissociate on copper surface initially and the methoxy fragment is the most abundant and stable intermediate. Formaldehyde is produced by the decomposition of the methoxy species when increasing the surface temperature of the copper surface.[13] The $\mathrm{CO}_{2}$ peak (mass 44) evolves at $395 \mathrm{~K}$. Wachs and Madix[6] concluded that the $\mathrm{CO}_{2}$ peak on their TPD spectra is from a very stable formate intermediate. While Bowker and 
Madix[13] inferred that the earlier report[6] of the formate intermediate is due to formaldehyde contamination in the methanol. More recent works[4, 36] clearly prove that the formate is produced during the methanol adsorption with the presence of oxygen on the copper surface. These recent studies indeed suggest that the $\mathrm{CO}_{2}$ peak originates from the formate intermediates.

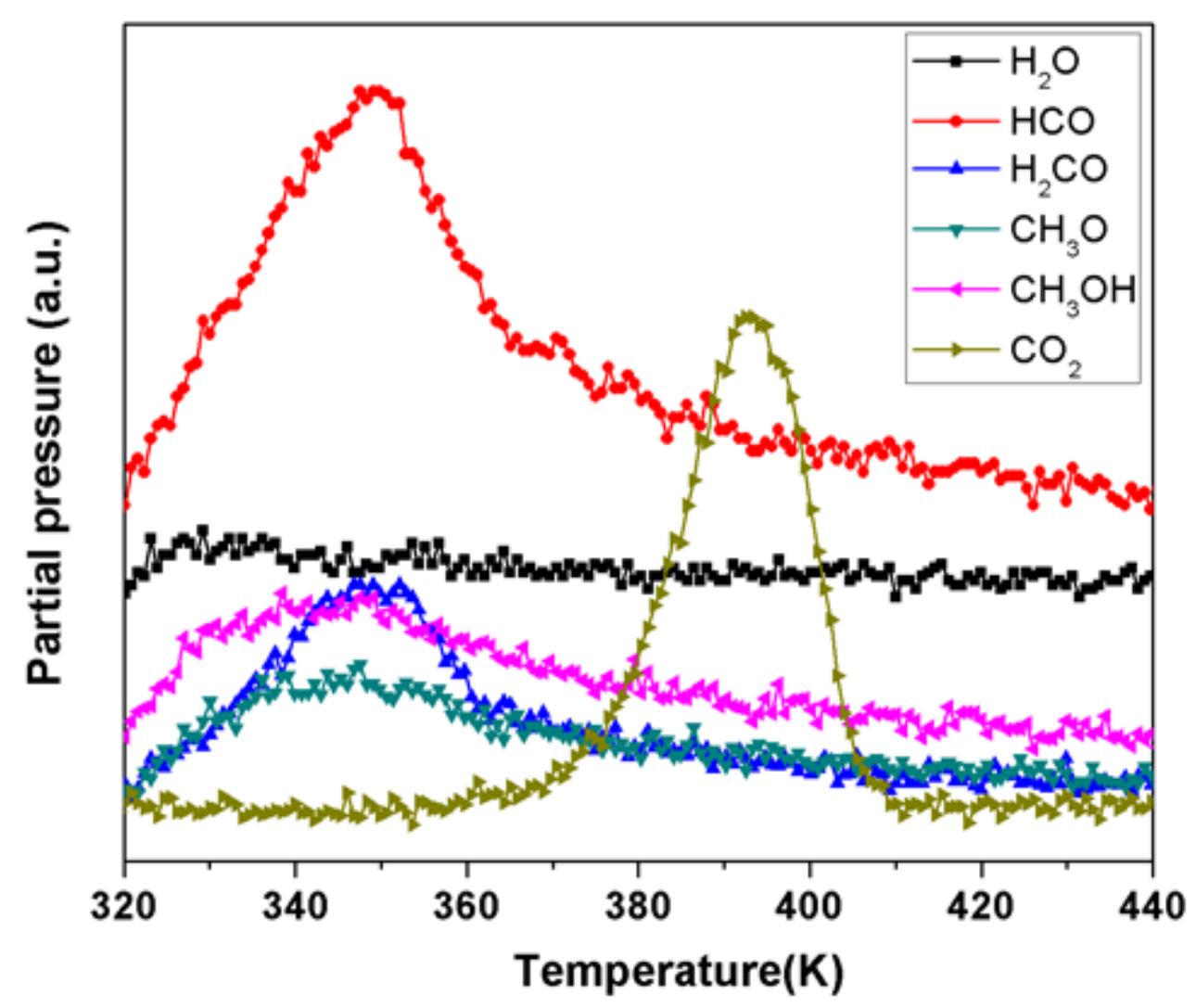

Figure 2. TPD profile from polycrystalline copper surface following 60 Langmuir methanol $\left(\mathrm{CH}_{3} \mathrm{OD}\right)$ gas adsorption at $300 \mathrm{~K}$. The masses correspond to the following desorption products: $\mathrm{H}_{2} \mathrm{O}$ (mass 18), $\mathrm{H}_{2} \mathrm{CO}$ (mass 28 and mass 29), $\mathrm{CH}_{3} \mathrm{OH}$ (mass 31 and mass 32), $\mathrm{CO}_{2}$ (mass 44). Heating rate was set at $1 \mathrm{~K} / \mathrm{s}$. 


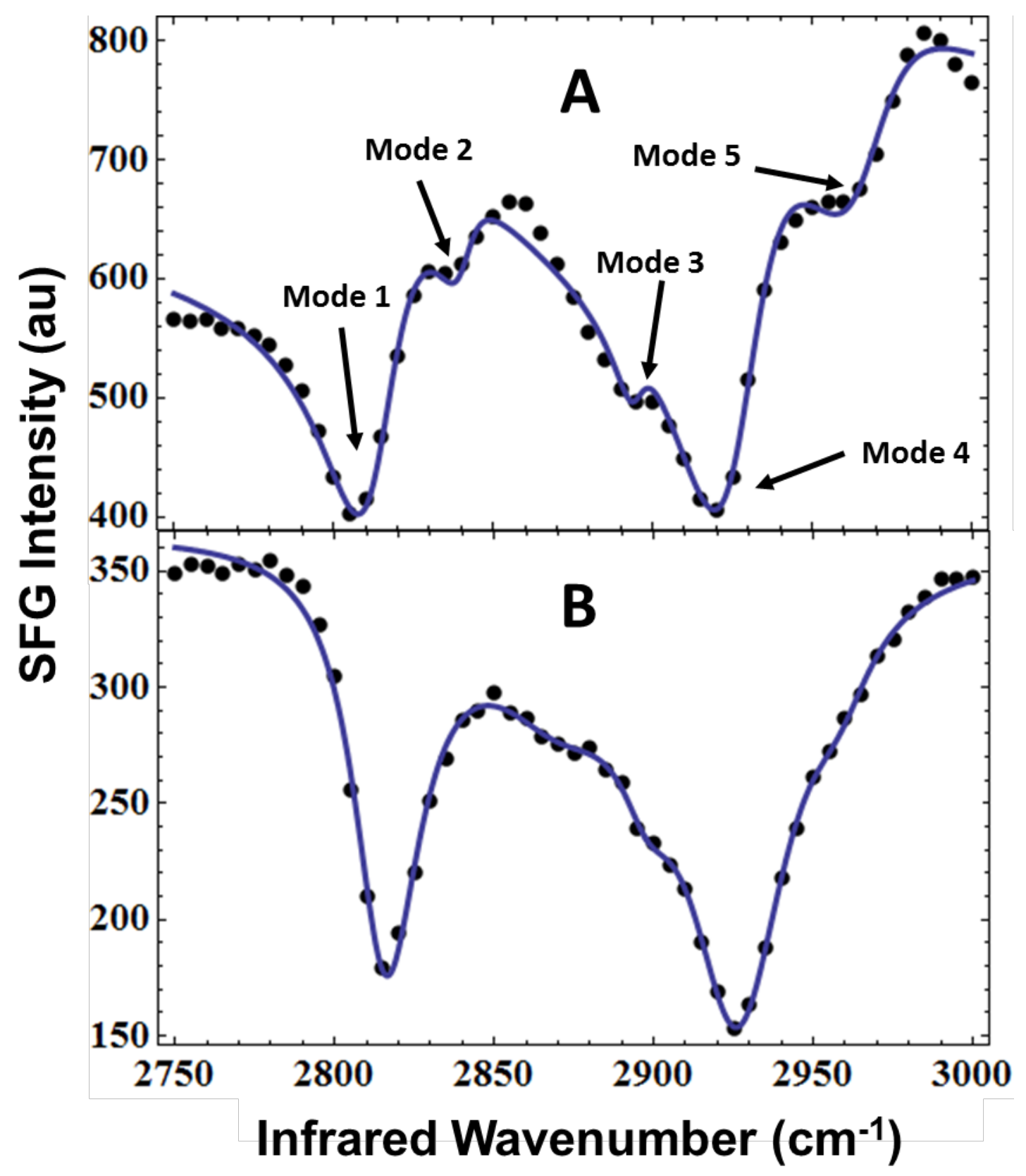

Figure 3. (A) The PPP-SFG spectrum of 1 Torr methanol $\left(\mathrm{CH}_{3} \mathrm{OD}\right)$ adsorption on copper surface from $2750 \mathrm{~cm}^{-1}$ to $3000 \mathrm{~cm}^{-1}$. (B) The PPP-SFG spectrum of 1 Torr methanol $\left(\mathrm{CH}_{3} \mathrm{OD}\right)$ and 800 Torr oxygen adsorption on copper from $2750 \mathrm{~cm}^{-1}$ to $3000 \mathrm{~cm}^{-1}$.

\subsection{SFG spectroscopy and peak assignment}

In situ SFG spectra $\left(2750-3050 \mathrm{~cm}^{-1}\right)$ of methanol $\left(\mathrm{CH}_{3} \mathrm{OD}\right)$ adsorption on copper surface are displayed in Figure 3. Two spectra in different gas exposure conditions 
are shown. The SFG spectrum in Figure 3A is obtained at room temperature from the copper substrate exposed to 1 Torr methanol $\left(\mathrm{CH}_{3} \mathrm{OD}\right)$ vapor until equilibrium. The SFG spectrum in Figure 3B is recorded from the copper substrate exposed to 1 Torr methanol $\left(\mathrm{CH}_{3} \mathrm{OD}\right)$ vapor and 800 Torr oxygen gas. There are five peaks (modes 1-5) which are located at $2812 \mathrm{~cm}^{-1}, 2860 \mathrm{~cm}^{-1}, 2890 \mathrm{~cm}^{-1}, 2925 \mathrm{~cm}^{-1}$, and $2960 \mathrm{~cm}^{-1}$, respectively.

Table 1: Fitting results of the SFG spectra sketched in Figure 3

\begin{tabular}{l|ccc|ccc}
\hline & \multicolumn{3}{c|}{$\begin{array}{c}\text { copper surface with } \mathrm{CH}_{3} \mathrm{OD} \\
\text { adsorption }\end{array}$} & \multicolumn{3}{c}{ copper oxide surface with } \\
& \multicolumn{3}{c}{$\mathrm{CH}_{3}$ OD adsorption } \\
\hline peak mode 1 & 2812 & $\mathrm{~A}_{\mathrm{q}}($ a.u. $)$ & $\Gamma_{\mathrm{q}}\left(\mathrm{cm}^{-1}\right)$ & $\omega_{\mathrm{q}}\left(\mathrm{cm}^{-1}\right)$ & $\mathrm{A}_{\mathrm{q}}($ a.u. $)$ & $\Gamma_{\mathrm{q}}\left(\mathrm{cm}^{-1}\right)$ \\
peak mode 2 & 2853 & 39 & 14 & 2813 & 73 & 12 \\
peak mode 3 & 2887 & 4 & 42 & 2862 & 54 & 29 \\
peak mode 4 & 2926 & 69 & 21 & 2894 & 12 & 11 \\
peak mode 5 & 2963 & 34 & 24 & 2956 & 103 & 18 \\
\end{tabular}

Based on previous studies[2,6] and the TPD results in this work, methoxy is the most abundant species on the copper surface following methanol $\left(\mathrm{CH}_{3} \mathrm{OD}\right)$ adsorption. Therefore, combined with previous assignments for SFG, HREELS, and IRAS results of methoxy on the copper surface, $[3,7,9,37]$ the strong peak at $2810 \mathrm{~cm}^{-1}$ is unambiguously assigned to the methyl symmetric stretching mode of methoxy group. An early IRAS study[37] of methanol adsorbed on $\mathrm{Cu}(100)$ attributed the observation of three modes $\left(2787,2861\right.$, and $\left.2901 \mathrm{~cm}^{-1}\right)$ in the IRAS spectra to methyl symmetric stretching mode and two degenerate methyl asymmetric stretching modes, respectively. However, Chesters and McCash proposed that the two vibrational mode, in higher wavenumber range of $\mathrm{C}-\mathrm{H}$ stretching region, were due to overtone and/or combination bands of the methyl deformation modes.[38] More recently, the studies performed by IRAS about methanol adsorption on a wide variety of copper surfaces listed in Table 2 make a good agreement with Chesters and McCash's work. According to IR selection rules, only the vibrational modes with component positioned along the surface normal could be observed by the IRAS. When the C-O axis is aligned along the surface normal, the asymmetric stretching mode is perpendicular to the surface normal and, therefore, expected not to appear in the IRAS spectra. Studies 
performed on $\mathrm{Cu}(110)[39]$ and $\mathrm{Cu}(111)[40]$ with X-ray absorption and backscattering photoelectron diffraction measurements demonstrated that the $\mathrm{C}-\mathrm{O}$ axis is nearly perpendicular to the copper surface. The peak around $2887 \mathrm{~cm}^{-1}$ and $2925 \mathrm{~cm}^{-1}$ are the Fermi resonance of the symmetric stretching mode with the overtone $\left(2 \delta_{\mathrm{s}}\right.$ and $\left.2 \delta_{\mathrm{as}}\right)$ of deformation mode of the methyl group, respectively. In this case, the mode 5 is assigned as the methyl asymmetric stretching mode $\left(v_{\mathrm{as}}\right)$.

Table 2: Infrared vibrational mode assignments for methoxy on metal surface

\begin{tabular}{|c|c|c|c|c|c|}
\hline & \multicolumn{5}{|c|}{ Vibrational peak assignments } \\
\hline & $\mathrm{Cu}(100)[37]$ & $\mathrm{Cu}(100)[41]$ & $\mathrm{Cu}(100)[42]$ & $\mathrm{Cu}(111)[43]$ & This work \\
\hline Fermi-[2 $\left.\delta_{\text {as }}\left(\mathrm{CH}_{3}\right)\right]$ & & 2911 & 2917 & 2918 & 2926 \\
\hline Fermi-[2 $\left.\delta_{\mathrm{s}}\left(\mathrm{CH}_{3}\right)\right]$ & & 2875 & 2879 & 2882 & 2887 \\
\hline$v_{\mathrm{s}}\left(\mathrm{CH}_{3}\right)$ & 2787 & 2798 & 2805 & 2818 & 2812 \\
\hline$v_{\mathrm{as}}\left(\mathrm{CH}_{3}\right)$ & $2861 \& 2901$ & & & & \\
\hline$\delta \mathrm{s}\left(\mathrm{CH}_{3}\right)$ & & & 1426 & & \\
\hline Fermi- $\left[2 \delta_{\mathrm{as}}\left(\mathrm{CD}_{3}\right)\right]$ & & 2171 & & 2183 & 2130 \\
\hline Fermi- $\left[2 \delta_{\mathrm{s}}\left(\mathrm{CD}_{3}\right)\right]$ & & 2171 & & 2183 & 2130 \\
\hline$v_{\mathrm{s}}\left(\mathrm{CD}_{3}\right)$ & 2054 & 2054 & & 2050 & 2044 \\
\hline$v_{\mathrm{as}}\left(\mathrm{CD}_{3}\right)$ & $2127 \& 2178$ & & & & \\
\hline$\delta_{\mathrm{s}}\left(\mathrm{CD}_{3}\right)$ & & & & 1130 & \\
\hline
\end{tabular}

In Figure 3, there is a small peak located around $2853 \mathrm{~cm}^{-1}$. Previous IRAS studies $[2,4]$ demonstrate the existence of small amounts of formate species bound to the surface at room temperature with excess surface oxygen. The TPD results in Figure 2 support the existence of formate in this system. Thus that the mode 2 is assigned to $v(\mathrm{CH})$ of formate.[10]

Figure 4 shows the SFG spectrum $\left(2000-2250 \mathrm{~cm}^{-1}\right)$ of methanol $\left(\mathrm{CD}_{3} \mathrm{OD}\right)$ adsorption on copper surface which is obtained at room temperature with 1 Torr methanol $\left(\mathrm{CD}_{3} \mathrm{OD}\right)$ vapor. The sharp peak located around $2044 \mathrm{~cm}^{-1}$ is assigned to the methyl symmetric stretching mode and the broad peak located at $2130 \mathrm{~cm}^{-1}$ is assigned as the Fermi resonance mode based on previous assignment listed in Table 4.[41] The SFG spectrum (2550-2700 $\left.\mathrm{cm}^{-1}\right)$ are featureless and shown in Figure S4. No OD stretching mode is observed which is consistent with previous IRAS studies. [37] 


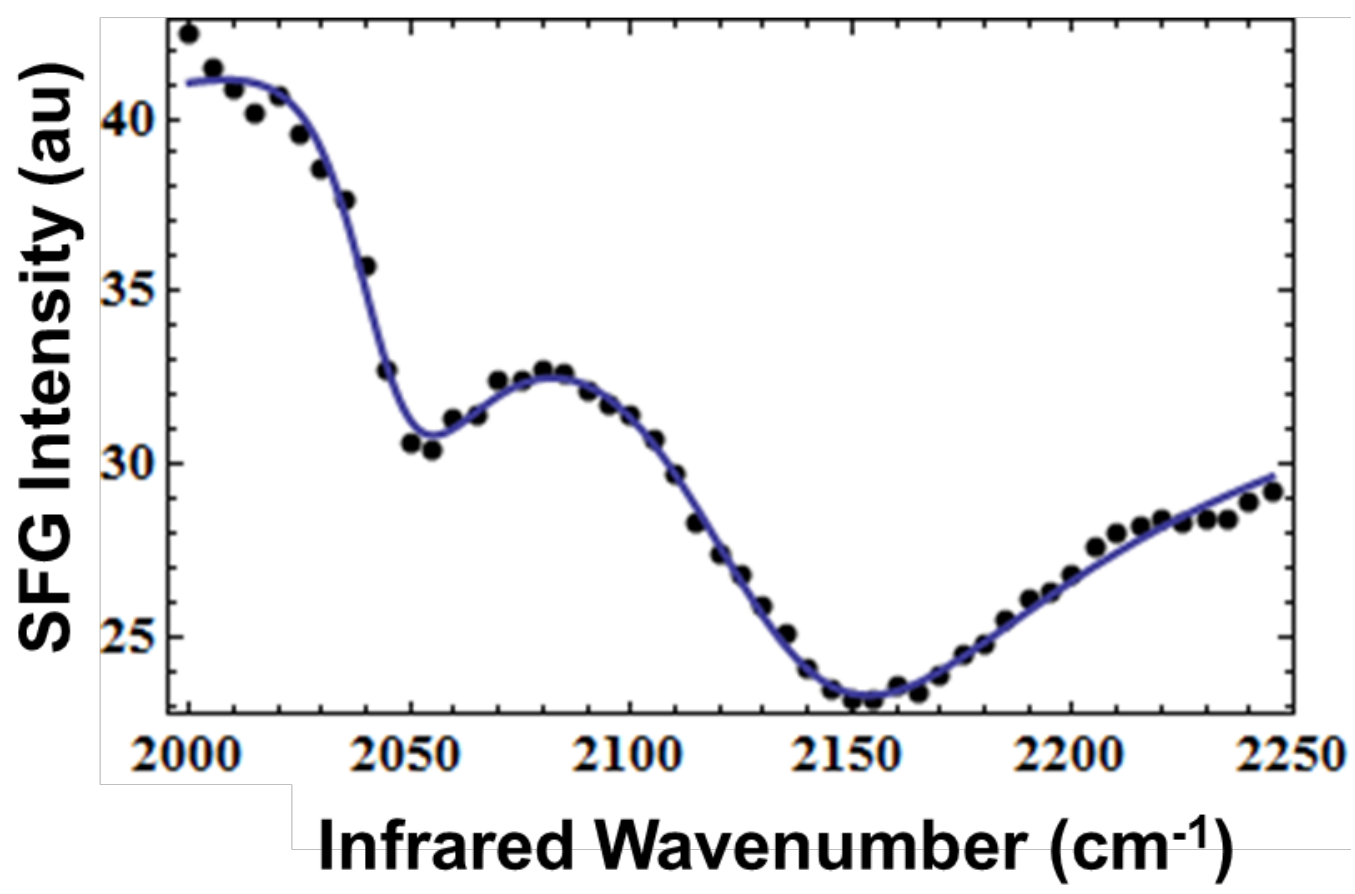

Figure 4. The PPP-SFG spectrum of 1 Torr methanol $\left(\mathrm{CD}_{3} \mathrm{OD}\right)$ adsorption on copper surface from $2000 \mathrm{~cm}^{-1}$ to $2250 \mathrm{~cm}^{-1}$.

Table 3: Fitting results of the SFG spectrum sketched in Figure 4

\begin{tabular}{l|ccc}
\hline & \multicolumn{3}{c}{ Pure copper with $\mathrm{CD}_{3}$ OD adsorption } \\
\cline { 2 - 4 } & $\omega_{\mathrm{q}}\left(\mathrm{cm}^{-1}\right)$ & $\mathrm{A}_{\mathrm{q}}($ a.u. $)$ & $\Gamma_{\mathrm{q}}\left(\mathrm{cm}^{-1}\right)$ \\
\hline Mode1 & 2044 & 16 & 19 \\
Mode2 & 2130 & 67 & 52
\end{tabular}

\subsection{Orientation calculation}




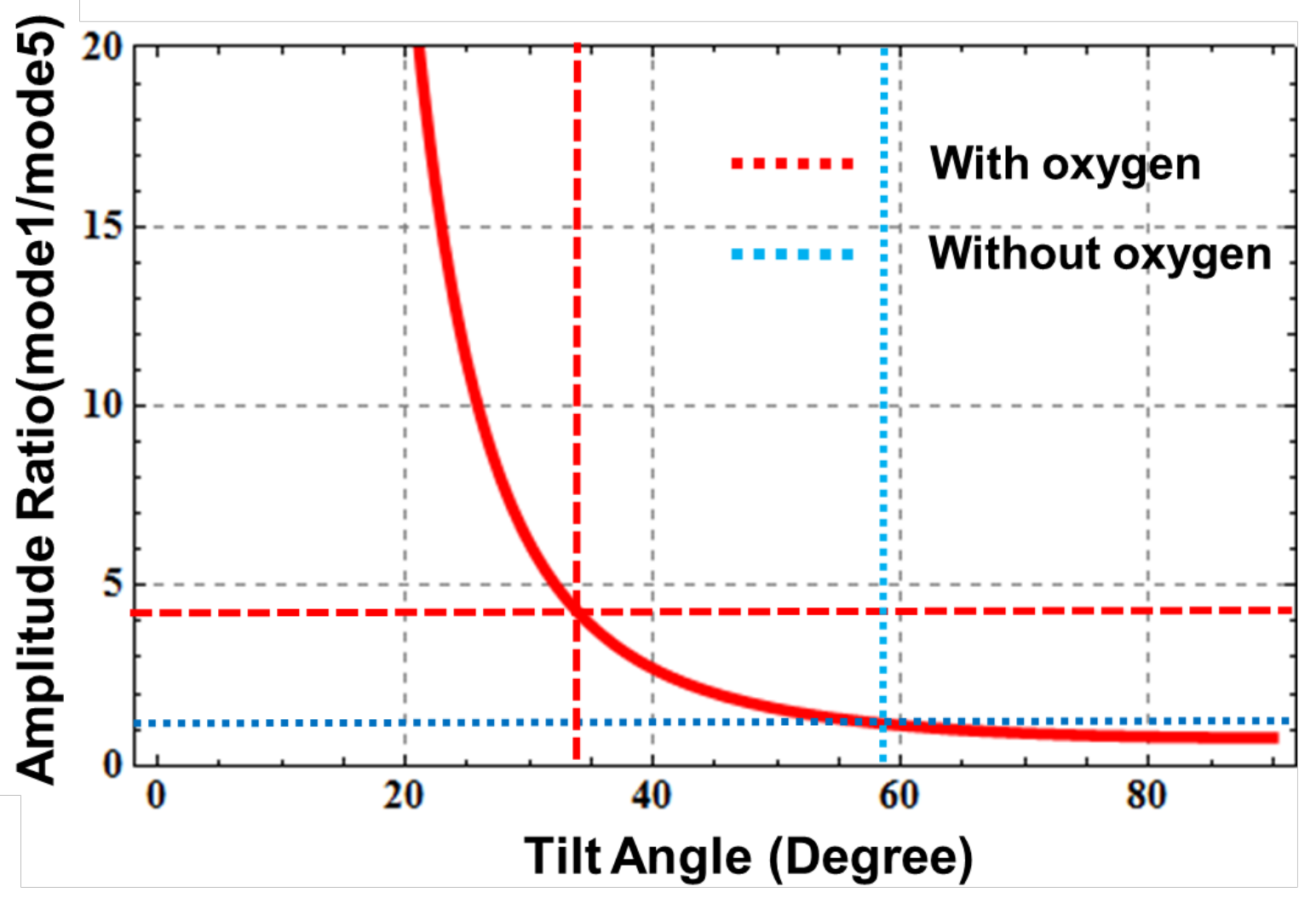

Figure 5. Orientation curve calculated by using the delta-function distribution approximation.

The orientation and conformation of the terminal methyl group on copper surface is very important to understand the molecular packing properties of the adsorbed monolayer. Thus an orientation analysis based on SFG spectra is performed in this work based on the amplitude ratio of $\mathrm{CH}_{3 \text {-sym }} / \mathrm{CH}_{3 \text {-asym }}$ of SFG spectrum under the PPP polarization combination.[44, 45] Detailed introduction of orientation analysis is provided in the Supporting Information. The tilt angle, azimuth angle and rotation angle reference to surface normal and $\mathrm{C}_{3}$ axis, are demonstrated in Figure 1. Based on the assumption that the tilt angle distribution of methoxy follows a $\delta$ function and the rotation angle together with azimuth angle are randomly distributed, a theoretical curve simulating the amplitude ratio of $\mathrm{CH}_{3 \text {-sym }} / \mathrm{CH}_{3 \text {-asym }}$ as a function of the tilt angle of methyl groups is presented in the Figure 5. In terms of fitting results and theoretical simulation curves, the tilt angle $(\Theta)$ of methyl group is around $59 \pm 7^{\circ}$ for copper without oxygen exposure, and $34 \pm 3^{\circ}$ for copper with oxygen exposure. 
The tilt angle of methoxy group on copper oxide surface is smaller than on pure copper surface might suggest that the methoxy group is more densely packed on oxidized copper. Previous studies demonstrated that oxygen promotes the methanol dissociation and increases the surface density of the methoxy monolayer on copper surface.[2, 6-8] Thus, higher density and smaller tilt angle of methoxy increase the cross section of methyl symmetric stretching mode on copper oxide surface relative to the pure copper surface.

\subsection{Spatial mapping and orientation distribution analysis}

Table 4. Non-resonant background and phase of copper and copper oxide

\begin{tabular}{l|cc}
\hline & Non-resonant intensity(a.u.) & Non-resonant phase- $\phi(\mathrm{rad})$ \\
\hline Pure copper & 26.7 & -2.75 \\
Copper oxide & 19.6 & -1.56
\end{tabular}

By fitting the SFG spectra in Figure 3 based on the Equation 4, the non-resonant background and non-resonant relative phase results are listed in Table 4. The intensity of non-resonant background of copper oxide is lower than the pure copper. The relative phase also changes after the introduction of oxygen. Previous studies indicate that the non-resonant background has a direct relationship with surface electronic properties of the metal substrate.[10, 32, 35, 46] The exposure of oxygen gas to pure copper would introduce the formation of copper oxide on surface,[47] which changes the surface electronic properties and non-resonant response.[46, 48] The SFG signal (IR wavenumber: $3000 \mathrm{~cm}^{-1}$ ) correlates with oxygen introduction time. This effect is demonstrated more clearly in Figure 6 . Since $3000 \mathrm{~cm}^{-1}$ is far from vibrational resonant region of methyl group, the SFG signal can be regarded as the contribution of non-resonant response from the substrate. Upon exposure with 800 Torr oxygen gas, the SFG intensity $\left(3000 \mathrm{~cm}^{-1}\right)$ quickly drops in the first 5 mins, then gradually decreases to a signal level which is half of the initial intensity. After half an hour, the SFG intensity remains stable. This observation is comparable with previous SHG studies of oxidation of $\mathrm{Cu}(111)$.[46] 


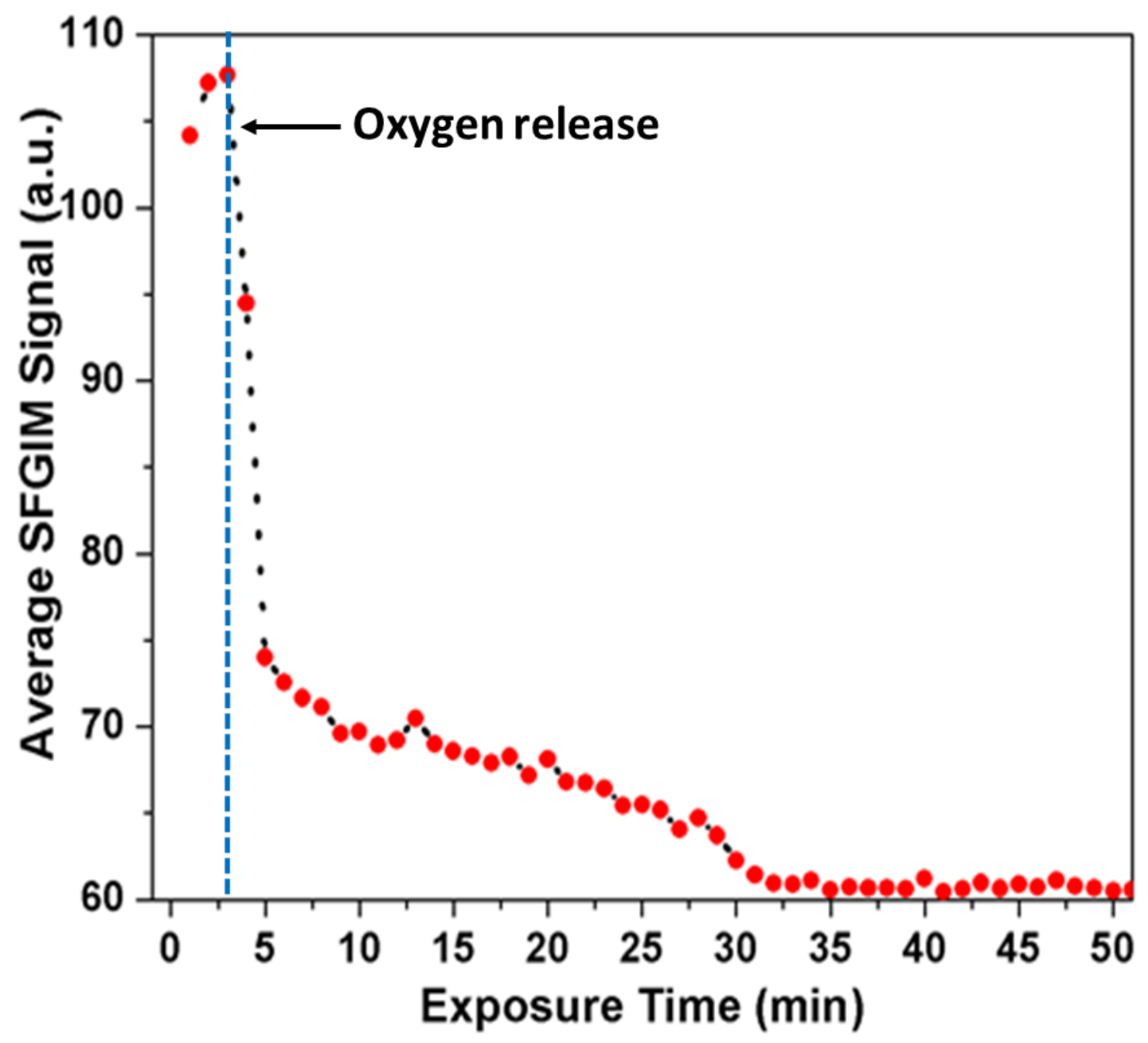

Figure 6. SFG non-resonant background intensity $\left(3000 \mathrm{~cm}^{-1}\right)$ changed as oxygen exposure time ( 800 Torr oxygen is released at the third minute)

From Equation 4, the relative phase $\phi$ results from interaction between the substrate and top methoxy monolayer, as evidenced by constructive or destructive interference between adjacent peaks as well as with the non-resonant background, causes spectral lineshape shifts as the relative phase changes. Recently, Hosseinpour et al.'s work reported that oxidation of the copper substrate significantly changes the SFG spectral line shape of alkanethiol SAMs on copper.[33] Santos et al. showed two-dimensional line-shape transformation of alkanethiol SAMs on copper surface using SFGIM.[49] Comparison of SFG spectra in Figure 3 indicates an alteration of the spectral line-shape with oxygen exposure. The phase parameters shown in Table 5 also denote the non-resonant phase shift from $-2.75 \mathrm{rad}$ to $-1.56 \mathrm{rad}$. These transformations of spectral features 
including the relative phase, non-resonant background and spectral line-shape reveal the high sensitivity of SFG signal to chemical changes on the metal surface.

The stack of SFG images is divided into $40 \times 40$ regions of interest (ROI) which is a $15 \mu \mathrm{m} \times 15 \mu \mathrm{m}$ square. The SFG spectra are extracted and fitted by Equation 2 . The fitting parameters including amplitude, non-resonant phase, resonant frequency and ratios of methyl symmetric stretching mode and methyl asymmetric stretching mode in each ROI are obtained and then used in the following statistics analysis. A $\delta$ function distribution is employed to analyze each ROI.

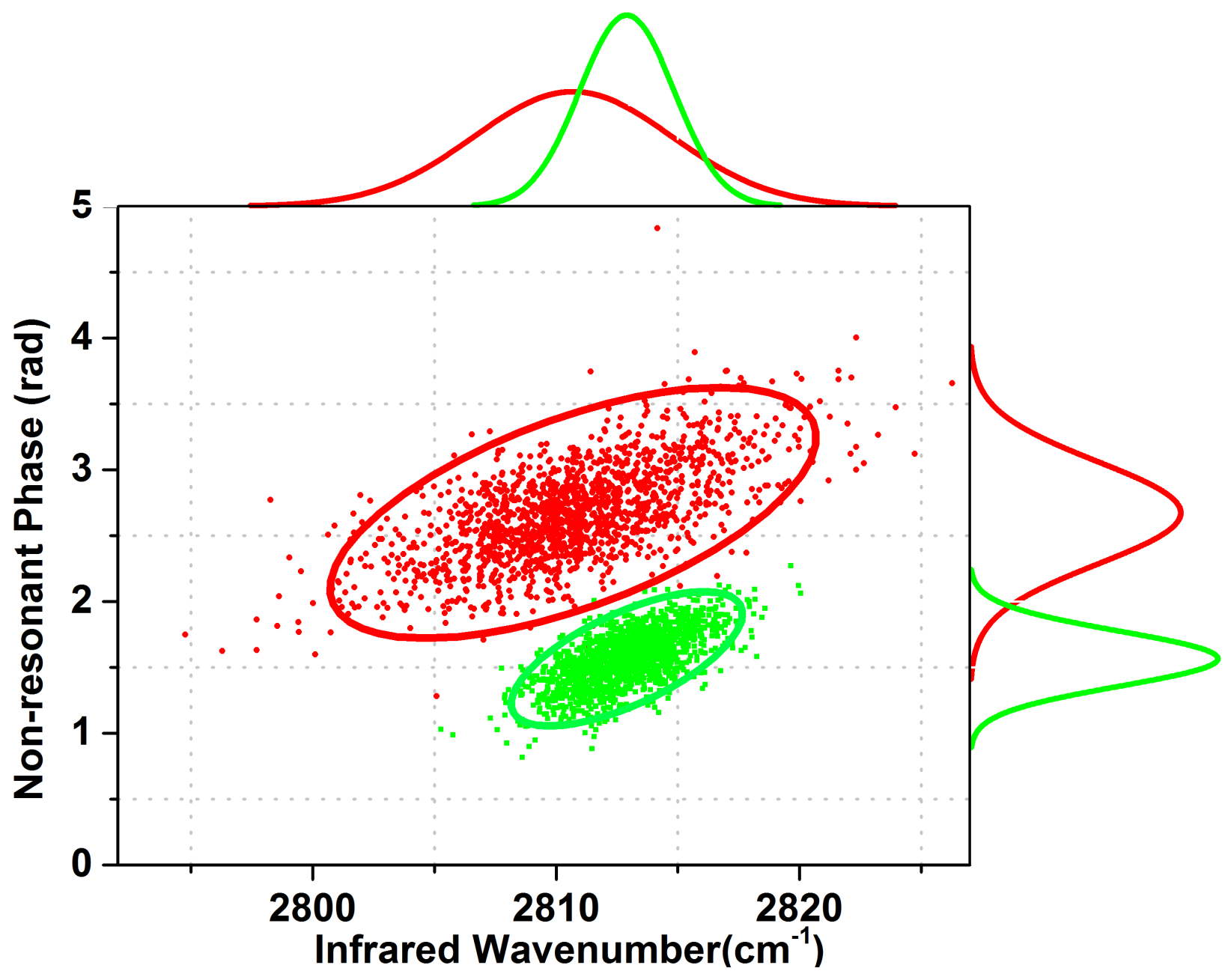

Figure 7. Scatter/marginal histogram plot of non-resonant phase vs $\mathrm{CH}_{3 \text {-sym }}$ resonant frequency (red data scatter points in red ellipse, as well as the red histogram line are for copper without oxygen; green data scatter points in green ellipse, as well as green histogram line are for copper with oxygen) 
In Figure 7, a scatter plot, as well as a marginal histogram, is constructed to correlate two spectral features: non-resonant phase vs $\mathrm{CH}_{3 \text {-sym }}$ resonant frequency. The $\mathrm{x}$-axis value and $\mathrm{y}$-axis value of each date point correspond to $\mathrm{CH}_{3 \text {-sym }}$ resonant frequency and non-resonant phase of a special ROI, respectively. The decrease in the distribution width of non-resonant phase and $\mathrm{CH}_{3 \text {-sym }}$ resonant frequency after introduction of oxygen suggests that heterogeneity of copper surface and methoxy monolayer decreases with the formation of copper oxide. Such a change could be related to the existence of various size of crystal domain with different surface atom structure on polycrystalline copper surface.[50-56] The formation of copper oxide generates a more homogenous surface atom structure arrangement, which narrows heterogeneity between different ROI.

In addition, there is a blue shift for the resonant wavenumber of $\mathrm{CH}_{3 \text {-sym }}$ concurrent with an overall increase in the non-resonant phase. The resonant frequency of $\mathrm{CH}_{3}$ sym stretching mode in the ROI with a higher non-resonant phase is higher than the ROI with a lower non-resonant phase. Known to be affected by the local surface structure of copper, the non-resonant phase could be spatially correlated with local bonding strength of methoxy. Such a relationship can be linked to the effects of various index crystal facets with the different binding energy of methoxy group. Similar phenomena were reported by Ertl et al. where different $\mathrm{CO}$ oxidation behavior are observed on the individual grains of the polycrystalline platinum surface.[57, 58] More recently, Salmeron et al. reported that the reaction rate difference of $\mathrm{CO}$ with chemisorbed oxygen on three low-index faces of copper resulted from different binding energy of oxygen.[59] Such mechanism of this phenomenon in this work need to be further explored to build an intrinsic correlation between copper surface structures with binding energy of methoxy group. However, this addresses the unique advantage of SFGIM in elucidating the relationship between the monolayer properties with local copper surface structure.

\subsection{Spatial maps of conformation and orientation of methoxy on copper surface}




\section{Pure Copper}
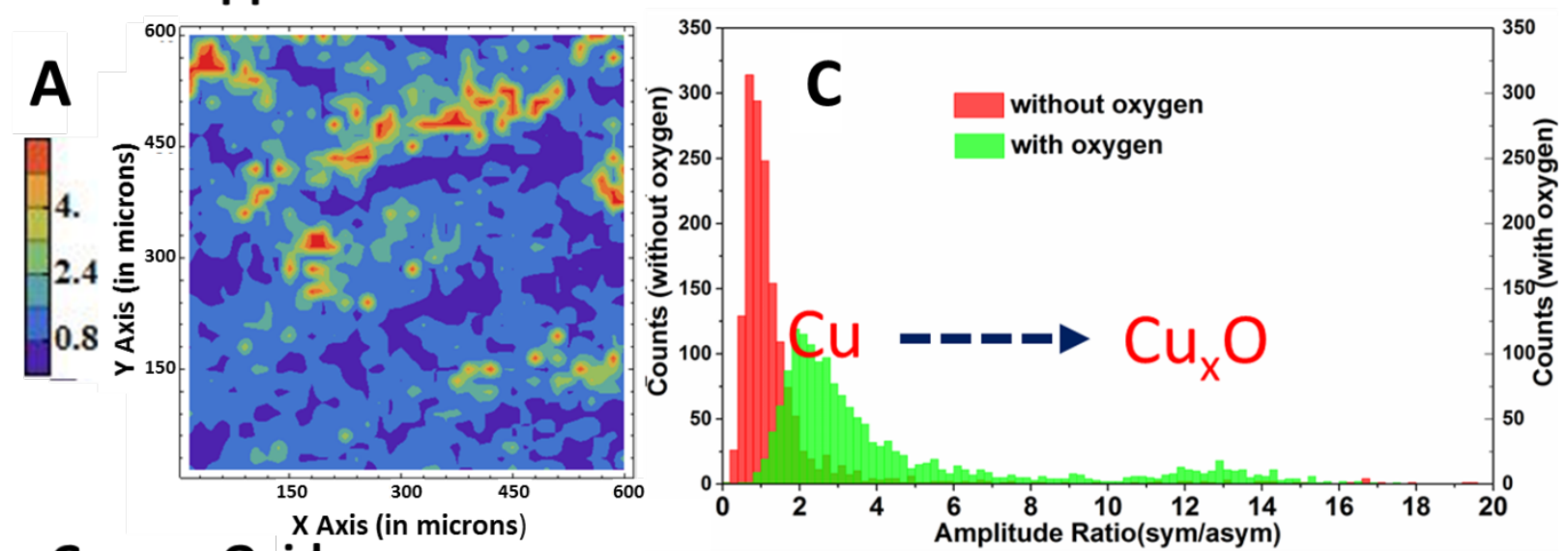

Copper Oxide
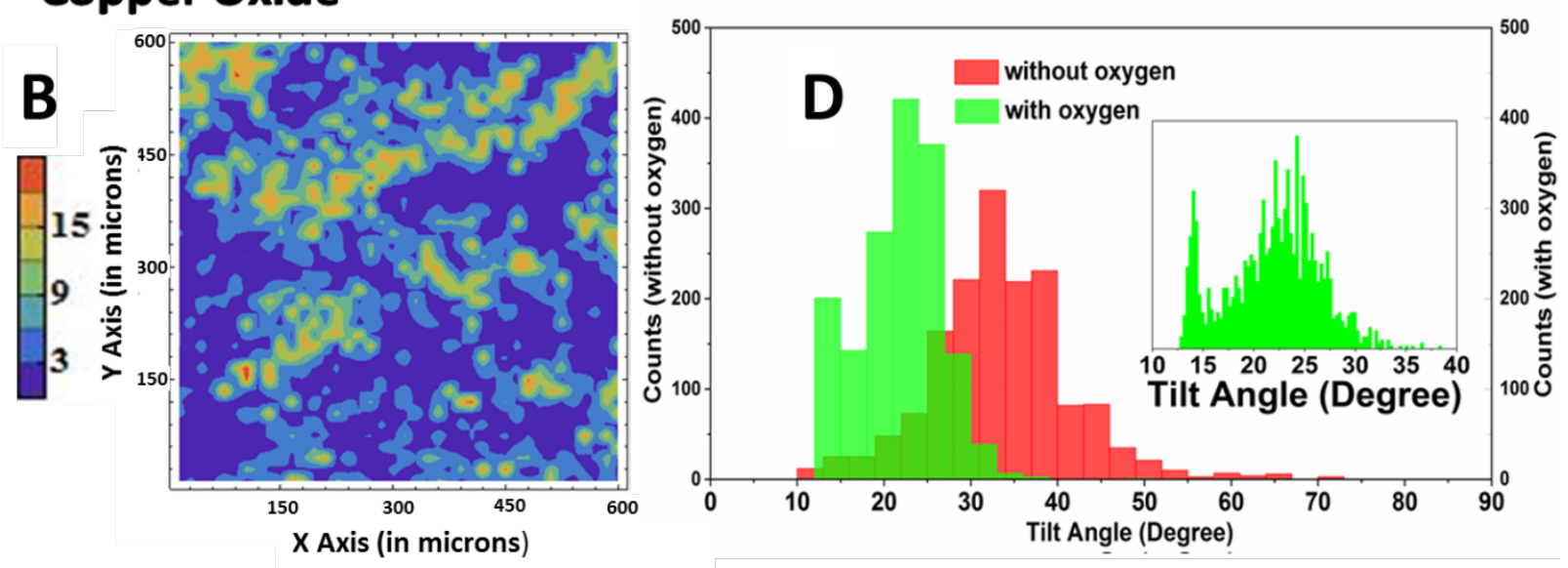

Figure 8. Contour maps of amplitude ratios of methoxy $\left(\mathrm{CH}_{3 \text {-sym }} / \mathrm{CH}_{3 \text {-asym }}\right)$ on copper (A) without and (B) with oxygen, respectively. Histogram of (C) amplitude ratios $\left(\mathrm{CH}_{3-\text {-sym }} / \mathrm{CH}_{3-\text {-asym }}\right)$ and (D) calculated tilt angle of methoxy on copper with (green) and without (red) oxygen, respectively.

To elucidate the role of oxygen in methoxy heterogeneity, the evaluation of SFGIM data from methanol $\left(\mathrm{CD}_{3} \mathrm{OD}\right)$ adsorption on copper with and without oxygen exposure is carried out by employing statistical methods represented in the form of spatial (contour maps) and histogram distributions. In Figure 8A and Figure $8 \mathrm{~B}$, the fitted results of the amplitude ratio $\left(\mathrm{CH}_{3 \text {-sym }} / \mathrm{CH}_{3 \text {-asym }}\right)$ is mapped onto the surface coordinates to visualize differences in spatial distribution for the copper surface with and without oxygen exposure. Inspection of the histogram of amplitude ratio in Figure $8 \mathrm{C}$, the initial ratio $\left(\mathrm{CH}_{3 \text {-sym }} / \mathrm{CH}_{3 \text {-asym }}\right)$ is narrowly distributed in the $0-4$ range. After the introduction of oxygen, the ratio distribution range increased up to 20 resulting to a wider bimodal distribution. 
It is suggested that the metal surface contains defects such as grain boundaries and/or phase inclusions which dramatically influence localized metal activity and, also, molecules adsorption at or near these sites.[49, 60-62] In considering defects, the oxidation process is not simultaneous and homogenous between different ROIs. Table 5 shows that the average ratio $\left(\mathrm{CH}_{3 \text {-sym }} / \mathrm{CH}_{3 \text {-asym }}\right)$ is lower for pure copper surface compared to copper oxide. The ratio $\left(\mathrm{CH}_{3 \text {-sym }} / \mathrm{CH}_{3 \text {-asym }}\right)$ is higher in the ROIs which are heavily oxidized compared to the lightly oxidized ROIs. Thus, in Figure $8 \mathrm{C}$, the extra broad peak of the histogram at higher ratio values corresponds to the ROIs that copper surface that are oxidized. While the main histogram peak centered at $\sim 3$ is attributed from ROIs in which the copper surface still remains metallic, the middle range of amplitude ratios between two peaks are linked to ROIs where the copper surface is partially oxidized.

The histogram of tilt angles in Figure 8D clearly demonstrates that methoxy group on copper oxide surface statistically lies more upright. The width of tilt angle distribution, a measure of the degree of monolayer order, suggests a more densely packed methoxy film with less monolayer defect following of oxidation. Since oxygen promotes the methanol dissociation and increases the surface density of the methoxy monolayer on copper surface,[2, 6-8] it could be inferred that higher surface density of molecules induces a compact monolayer with less monolayer defect, as well as a narrow distribution of tilt angle.

It is interesting to note that the distribution width of the ratio $\left(\mathrm{CH}_{3 \text {-sym }} / \mathrm{CH}_{3 \text {-asym }}\right)$ sketched in Figure 8 and Table 5 increases after the oxygen exposure. Intuitively, oxygen exposure narrows the tilt angle distribution of the methoxy group, and then also narrows the distribution of ratio $\left(\mathrm{CH}_{3 \text {-sym }} / \mathrm{CH}_{3 \text {-asym }}\right)$. However, it has to be noted that at higher values of the methyl (sym/asym) amplitude ratio, the range of possible angles is narrower based on simulation curve shown in Figure 5. Therefore evaluating the orientation distribution based on the simple comparison of the distribution width of the ratio $\left(\mathrm{CH}_{3 \text {-sym }} / \mathrm{CH}_{3 \text {-asym }}\right)$ is not accurate. These statistical analysis address that SFGIM improves the understanding of role of oxygen in methanol adsorption on copper surface by analyzing each ROI separately.

Table 5. Statistical parameters of distributions of the methyl (sym/asym) ratio and terminal methyl group tilt angle (degree) 


\begin{tabular}{l|ccccc}
\hline & \multicolumn{2}{c}{ Methyl (sym/asym) Ratio } & $\begin{array}{l}\text { Methyl } \\
(\text { degree })\end{array}$ & group tilt angle \\
\cline { 2 - 5 } & Mean & Distribution width $(\sigma)$ & Mean & Distribution width $(\sigma)$ \\
\hline Pure Copper & 1.8 & 3.0 & 65 & 21 \\
Copper Oxide & 6.6 & 4.5 & 34 & 12 \\
\hline
\end{tabular}

\section{Conclusions}

This work demonstrates the high sensitivity of SFGIM in evaluating the quality and structure of monolayer film, as well as spatially correlating the local substrate with the top monolayer performance. At first, the spontaneous methanol dissociation and methoxy monolayer formation at room temperature is observed on copper surface. Comparison of SFG spectra elucidates oxygen exposure decrease the tilt angle of methoxy monolayer which is closer to the surface normal. Statistical analysis of SFG images suggests a well ordered methoxy monolayer with less defects following the oxygen exposure. Spatial correlation between nonresonant phases with resonant frequency of methoxy symmetric stretching mode demonstrate the potential of SFGIM to correlate the local substrate to molecular behavior of top methoxy monolayer. This study provides a new clue for the future research of heterogeneous catalysis system as well as understanding metal surface in the molecular level.

\section{Acknowledgements}

We gratefully acknowledge the National Science Foundation (CHE1361885) for providing generous support for this project. We also appreciate valuable work on UHV system from Dr. Boris Makarenko and Mr. Mark Bushman. We also thank for Dr. Joonhee Jang for developing out of Mathematica program for SFG imaging analysis. M.F. acknowledges valuable suggestions from Dr.Zefeng Ren (Peking University) and Xin Tang (John Hopkins University) about UHV system.

\section{References:}

[1] C.N. Satterfield, Heterogeneous catalysis in practice, McGraw-Hill Companies, 1980.

[2] W. Sim, P. Gardner, D. King, Structure and reactivity of the surface methoxy species on Ag $\{111\}$, J. Phys. Chem. , 99 (1995) 16002-16010.

[3] J. Camplin, E. McCash, A RAIRS study of methoxy and ethoxy on oxidised Cu (100), Surf. Sci., 360 (1996) 229-241. 
[4] K. Mudalige, M. Trenary, Identification of formate from methanol oxidation on $\mathrm{Cu}(100)$ with infrared spectroscopy, Surf. Sci., 504 (2002) 208-214.

[5] J. Yoshihara, S. Parker, A. Schafer, C.T. Campbell, Methanol synthesis and reverse water-gas shift kinetics over clean polycrystalline copper, Catal. Lett., 31 (1995) 313-324.

[6] I.E. Wachs, R.J. Madix, The selective oxidation of $\mathrm{CH} 3 \mathrm{OH}$ to $\mathrm{H} 2 \mathrm{CO}$ on a copper(110) catalyst, J. Catal., 53 (1978) 208-227.

[7] B.A. Sexton, Surface vibrations of adsorbed intermediates in the reaction of alcohols with $\mathrm{Cu}(100)$, Surf. Sci., 88 (1979) 299-318.

[8] J. Russell Jr, S.M. Gates, J. Yates Jr, Reaction of methanol with Cu (111) and Cu (111)+ O (ads), Surf. Sci., 163 (1985) 516-540.

[9] K. Mudalige, M. Trenary, The formation of methoxy from methanol on an oxygen covered $\mathrm{Cu}$ (100) surface at temperatures of 90-200 K, J. Phys. Chem. B, 105 (2001) 3823-3827.

[10] S. Lin, A. Oldfield, D. Klenerman, In-situ studies of polycrystalline copper during methanol synthesis at high pressure using sum frequency generation at surfaces, Surf. Sci., 464 (2000) 1-7.

[11] X. Jiang, J.E. Parmeter, C.A. Estrada, D.W. Goodman, The adsorption and decomposition of methanol on copper overlayers on the Rh (100) surface, Surf. Sci., 249 (1991) 44-60.

[12] S.S. Fu, G.A. Somorjai, Roles of chemisorbed oxygen and zinc oxide islands on copper (110) surfaces for methanol decomposition, J. Phys. Chem., 96 (1992) 4542-4549.

[13] M. Bowker, R.J. Madix, XPS, UPS and thermal desorption studies of alcohol adsorption on $\mathrm{Cu}(110)$ : I. Methanol, Surf. Sci., 95 (1980) 190-206.

[14] H. Härle, A. Lehnert, U. Metka, H.-R. Volpp, L. Willms, J. Wolfrum, In-situ detection of chemisorbed $\mathrm{CO}$ on a polycrystalline platinum foil using infrared-visible sum-frequency generation, Chem. Phys. Lett., 293 (1998) 26-32.

[15] G.A. Somorjai, G. Rupprechter, Molecular studies of catalytic reactions on crystal surfaces at high pressures and high temperatures by infrared-visible sum frequency generation (SFG) surface vibrational spectroscopy, J. Phys. Chem. B, 103 (1999) 1623-1638.

[16] C. Pérez León, C. Sürgers, H. v. Löhneysen, Formation of copper oxide surface structures via pulse injection of air onto $\mathrm{Cu}(111)$ surfaces, Phys. Rev. B 85 (2012) 035434.

[17] Y.-G. Kim, J.H. Baricuatro, A. Javier, J.M. Gregoire, M.P. Soriaga, The Evolution of the Polycrystalline Copper Surface, First to $\mathrm{Cu}(111)$ and Then to $\mathrm{Cu}(100)$, at a Fixed CO2RR Potential: A Study by Operando EC-STM, Langmuir, 30 (2014) 15053-15056.

[18] X.C. Su, P.S. Cremer, Y.R. Shen, G.A. Somorjai, High-pressure CO oxidation on Pt(111) monitored with infrared-visible sum frequency generation (SFG), J. Am. Chem. Soc., 119 (1997) 3994-4000.

[19] P.S. Cremer, X.C. Su, Y.R. Shen, G.A. Somorjai, Ethylene hydrogenation on Pt(111) monitored in situ at high pressures using sum frequency generation, J. Am. Chem. Soc., 118 (1996) 2942-2949.

[20] C.-y. Wang, H. Groenzin, M.J. Shultz, Molecular Species on Nanoparticulate Anatase TiO2 Film Detected by Sum Frequency Generation: Trace Hydrocarbons and Hydroxyl Groups, Langmuir, 19 (2003) 7330-7334.

[21] R.-r. Feng, A.-a. Liu, S. Liu, J. Shi, R. Zhang, Z. Ren, In situ studies on the dissociation and photocatalytic reactions of $\mathrm{CH} 3 \mathrm{OH}$ on $\mathrm{TiO} 2$ thin film by sum frequency generation vibrational spectroscopy, J. Phys. Chem. C, 119 (2015) 9798-9804.

[22] K. Cimatu, S. Baldelli, Sum frequency generation microscopy of microcontact-printed mixed selfassembled monolayers, J. Phys. Chem. B, 110 (2006) 1807-1813.

[23] J.H. Jang, J. Jacob, G. Santos, T.R. Lee, S. Baldelli, Image contrast in sum frequency generation microscopy based on monolayer order and coverage, J. Phys. Chem. C, 117 (2013) 15192-15202.

[24] C.D. Bain, Sum-frequency vibrational spectroscopy of the solid/liquid interface, J. Chem. Soc. Faraday Trans., 91 (1995) 1281-1296. 
[25] Y. Shen, Surface properties probed by second-harmonic and sum-frequency generation, Nature, 337 (1989) 519-525.

[26] M. Buck, M. Himmelhaus, Vibrational spectroscopy of interfaces by infrared-visible sum frequency generation, J. Vac. Sci. Technol. A, 19 (2001) 2717-2736.

[27] G. Santos, S. Baldelli, Scale dependence of the orientation and conformation distribution analysis of a molecular monolayer using sum frequency generation imaging microscopy, J. Phys. Chem. C, 116 (2012) 25874-25887.

[28] A.G. Lambert, P.B. Davies, D.J. Neivandt, Implementing the theory of sum frequency generation vibrational spectroscopy: A tutorial review, Appl. Spectrosc. Rev., 40 (2005) 103-145.

[29] M. Buck, M. Himmelhaus, Vibrational spectroscopy of interfaces by infrared-visible sum frequency generation, J. Vac. Sci. Technol. A-Vac. Surf. Films, 19 (2001) 2717-2736.

[30] Y.R. Shen, SURFACE-PROPERTIES PROBED BY 2ND-HARMONIC AND SUM-FREQUENCY GENERATION, Nature, 337 (1989) 519-525.

[31] X. Zhu, H. Suhr, Y. Shen, Surface vibrational spectroscopy by infrared-visible sum frequency generation, Phys. Rev. B, 35 (1987) 3047.

[32] A.L. Harris, C.E.D. Chidsey, N.J. Levinos, D.N. Loiacono, Monolayer vibrational spectroscopy by infrared-visible sum generation at metal and semiconductor surfaces, Chem. Phys. Lett., 141 (1987) 350356.

[33] S. Hosseinpour, J. Hedberg, S. Baldelli, C. Leygraf, M. Johnson, Initial Oxidation of AlkanethiolCovered Copper Studied by Vibrational Sum Frequency Spectroscopy, Journal of Physical Chemistry C, 115 (2011) 23871-23879.

[34] M. Fang, S. Baldelli, Grain structures and boundaries on microcrystalline copper covered with an octadecanethiol monolayer revealed by sum frequency generation microscopy, J. Phys. Chem. Lett., 6 (2015) 1454-1460.

[35] R. Superfine, P. Guyotsionnest, J.H. Hunt, C.T. Kao, Y.R. Shen, Surface vibrational spectroscopy of molecular adsorbates on metals and semiconductors by infrared-visible sum-frequency generation, Surf. Sci., 200 (1988) L445-L450.

[36] P.R. Davies, G.G. Mariotti, Oxidation of methanol at $\mathrm{Cu}(110)$ surfaces: new TPD studies, J. Phys. Chem. , 100 (1996) 19975-19980.

[37] R. Ryberg, Symmetry and orientation of CH $3 \mathrm{O}$ on Cu (100), Physical Review B, 31 (1985) 2545.

[38] M.A. Chesters, E.M. McCash, The adsorption and reaction of methanol on oxidized copper (111) studied by Fourier transform reflection-absorption infrared spectroscopy, Spectrochim. Acta A, 43 (1987) 1625-1630.

[39] T. Lindner, J. Somers, A. Bradshaw, A. Kilcoyne, D. Woodruff, A photoelectron diffraction and nexafs study of the structure of the methoxy species ( $\mathrm{CH}<\mathrm{sub}>3</$ sub $>0-)$ on $\mathrm{Cu}\{100\}$, Surf. Sci., 203 (1988) 333-352.

[40] M. Witko, K. Hermann, D. Ricken, W. Stenzel, H. Conrad, A. Bradshaw, The electronic structure of the surface methoxy species on $\mathrm{Cu}\{111\}$, Chem. Phys., 177 (1993) 363-371.

[41] K. Mudalige, S. Warren, M. Trenary, Vibrational analysis of a chemisorbed polyatomic molecule: Methoxy on Cu (100), J. Phys. Chem. B, 104 (2000) 2448-2459.

[42] R. Asmundsson, P. Uvdal, Fermi resonance coupling in a surface adsorbate: The C-H stretch in methoxy adsorbed on $\mathrm{Cu}(100)$ calculations and experiments, J. Chem. Phys., 112 (2000) 366-372.

[43] M.A. Chesters, E.M. McCash, The adsorption and reaction of methanol on oxidized copper (111) studied by Fourier transform reflection-absorption infrared spectroscopy, Spectrochimica Acta Part A: Molecular Spectroscopy, 43 (1987) 1625-1630.

[44] C. Hirose, H. Yamamoto, N. Akamatsu, K. Domen, Orientation analysis by simulation of vibrational sum frequency generation spectrum: $\mathrm{CH}$ stretching bands of the methyl group, J. Phys. Chem. , 97 (1993) 10064-10069. 
[45] H.-F. Wang*, W. Gan, R. Lu, Y. Rao, B.-H. Wu, Quantitative spectral and orientational analysis in surface sum frequency generation vibrational spectroscopy (SFG-VS), Int. Rev. Phys. Chem., 24 (2005) 191-256.

[46] J. Bloch, D.J. Bottomley, S. Janz, H.M. Vandriel, Detection of subsurface oxygen on Cu(111): correlation of second-harmonic generation and Auger electron spectroscopy observations, Surf. Sci., 257 (1991) 328-334.

[47] T. Aastrup, M. Wadsak, M. Schreiner, C. Leygraf, Experimental in situ studies of copper exposed to humidified air, Corros. Sci., 42 (2000) 957-967.

[48] H.W.K. Tom, C.M. Mate, X.D. Zhu, J.E. Crowell, T.F. Heinz, G.A. Somorjai, Y.R. Shen, Surface studies by optical second-harmonic generation: the adsorption of $\mathrm{O} 2, \mathrm{CO}$, and sodium on the Rh(111) surface, Phys. Rev. Lett., 52 (1984) 348-351.

[49] G.M. Santos, S. Baldelli, Monitoring Localized Initial Atmospheric Corrosion of Alkanethiol-Covered Copper Using Sum Frequency Generation Imaging Microscopy: Relation between Monolayer Properties and Cu2O Formation, Journal of Physical Chemistry C, 117 (2013) 17591-17602.

[50] E. Martinez-Lombardia, V. Maurice, L. Lapeire, I. De Graeve, K. Verbeken, L. Kestens, P. Marcus, H. Terryn, In situ scanning tunneling microscopy study of grain-dependent corrosion on microcrystalline copper, J. Phys. Chem. C, 118 (2014) 25421-25428.

[51] L. Lapeire, E. Martinez Lombardia, K. Verbeken, I. De Graeve, L.A.I. Kestens, H. Terryn, Effect of neighboring grains on the microscopic corrosion behavior of a grain in polycrystalline copper, Corros. Sci., 67 (2013) 179-183.

[52] C.J. Park, M.M. Lohrengel, T. Hamelmann, M. Pilaski, H.S. Kwon, Grain-dependent passivation of surfaces of polycrystalline zinc, Electrochim. Acta, 47 (2002) 3395-3399.

[53] E. Martinez-Lombardia, L. Lapeire, V. Maurice, I. De Graeve, K. Verbeken, L.H. Klein, L.A.I. Kestens, P. Marcus, H. Terryn, In situ scanning tunneling microscopy study of the intergranular corrosion of copper, Electrochem. Commun., 41 (2014) 1-4.

[54] E. Martinez-Lombardia, Y. Gonzalez-Garcia, L. Lapeire, I. De Graeve, K. Verbeken, L. Kestens, J.M.C. Mol, H. Terryn, Scanning electrochemical microscopy to study the effect of crystallographic orientation on the electrochemical activity of pure copper, Electrochim. Acta, 116 (2014) 89-96.

[55] A. Schreiber, J.W. Schultze, M.M. Lohrengel, F. Karman, E. Kalman, Grain dependent electrochemical investigations on pure iron in acetate buffer pH 6.0, Electrochim. Acta, 51 (2006) 26252630.

[56] K.A. Lill, A.W. Hassel, G. Frommeyer, M. Stratmann, Scanning droplet cell investigations on single grains of a FeAICr light weight ferritic steel, Electrochim. Acta, 51 (2005) 978-983.

[57] G. Ertl, Oscillatory kinetics and spatio-temporal self-organization in reactions at solid surfaces, Science, 254 (1991) 1750-1755.

[58] J. Lauterbach, G. Haas, H. Rotermund, G. Ertl, Spatio-temporal pattern formation on polycrystalline platinum surfaces during catalytic CO oxidation, Surf. Sci., 294 (1993) 116-130.

[59] B. Eren, L. Lichtenstein, C.H. Wu, H. Bluhm, G.A. Somorjai, M. Salmeron, Reaction of CO with preadsorbed oxygen on low-index copper surfaces: an ambient pressure X-ray photoelectron spectroscopy and scanning tunneling microscopy study, J. Phys. Chem. C, 119 (2015) 14669-14674.

[60] D.A. Jones, Principles and prevention of corrosion, Macmillan, 1992.

[61] P.R. Roberge, Corrosion engineering: principles and practice, McGraw-Hill New York, 2008.

[62] K. Cimatu, S. Baldelli, Spatially resolved surface analysis of an octadecanethiol self-assembled monolayer on mild steel using sum frequency generation imaging microscopy, J. Phys. Chem. C, 111 (2007) 7137-7143. 